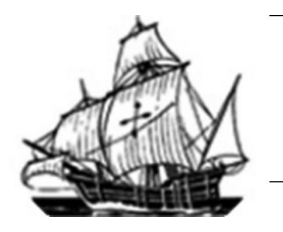

\title{
Leitura(s) de O Gato e o Escuro, de Mia Couto
}

\author{
Flavio García (UERJ) \\ Luciana Morais da Silva (UERJ)
}

\begin{abstract}
Resumo: O escritor moçambicano Mia Couto convida seu leitor a adentrar novas e outras sendas, transportando-se por (re)invenções da linguagem, segundo ele, mais suas, portanto, singulares. Ao produzir veredas imagéticas e caminhar por essa língua mais sua, marcada culturalmente, Mia revela um pouco de si e, também, do Outro, que está fora e dentro, compondo-o. Ao fazer isso, torna, por exemplo, perceptíveis os sentidos reticentes na escritura de $O$ gato e o escuro, narrativa apresentada na edição brasileira como infantil, na qual um jovem gatinho, à semelhança do próprio Mia, revela sua curiosidade de caminhar pelo "outro lado", tocando os muros que se interpõem entre o seu Eu e o (seu) Outro. O Escuro, personificado, lamenta sua condição, aparentemente invejada pelo Pintalgatinho curioso. Mas, com possibilidades mescladas e espaços de troca e hibridismo, os mundos de "lá" e "cá" se completam, do mesmo modo que as estruturas e vivências do mundo empírico e, por que não, do metaempírico, de que se nutre o artista moçambicano. Tal se pode contemplar em seus textos de opinião, em que permite se leiam ancestralidades vivenciadas pelo sonho, imaginação, bem ao gosto do Pintalgato.
\end{abstract}

Palavras-chave: literatura infantil moçambicana; narrativa moçambicana; ficção autobiográfica; $O$ Gato e o Escuro; Mia Couto.

\begin{abstract}
The Mozambican writer Mia Couto invites his reader to enter new and other paths, carrying up to (re) invention of language, according to him, more him, therefore, unique. By producing imagery and walking paths for that language more him, culturally marked, Mia reveals a little about himself and also the Other, which is outside and inside, making him. By doing so, he makes, for example, noticeable the reticent senses in the writing of "O gato e o escuro", narrative presented in the Brazilian edition as childish, in which a young kitten, like Mia himself, reveals his curiosity by walking "across", touching the walls that stand between his Self and (his) Other. The "dark", personified, laments his condition apparently envied by curious Pintalgatinho. But, with mixed possibilities and spaces for exchange and hybridity, the worlds of "there" and "here" complement themselves, the same way that the structures and experiences of the empirical world and, why not, the metaempirical, that feed the Mozambican artist. This can be contemplated in his opinion texts, which allows to read ancestries lived by the dream, imagination, and the taste of Pintalgato.
\end{abstract}

Keywords: children's literature Mozambique; Mozambican narrative; autobiographical fiction, $O$ Gato e o Escuro; Mia Couto. 
Meu desejo é desalisar a linguagem, colocando nela as quantas dimensões da vida. E quantas são? Se a vida tem, é idimensões? Assim embarco nesse gozo de ver como a escrita e o mundo mutuamente se desobedecem. (COUTO, 1997)

Mia Couto, em suas obras, sejam as de ficção ou de "opinião", caminha tecendo como fiandeira, de modo tão característico e marcado culturalmente, que a beleza dos fios com que tece suas narrativas - ou mesmo suas poesias, de que, aqui, não se falará - encanta tanto pelos detalhes, quanto pela gradação do trabalho artístico que as mãos do artista se lhes impõem.

Mia toma para si a tarefa de "desalisar" a linguagem, a partir de seu uso quotidiano, na concepção do signo linguístico, conforme o descreveu Roland Barthes, quando destacou que "os signos de que a língua é feita, os signos só existem na medida em que são reconhecidos, isto é, na medida em que se repetem; o signo é seguidor, gregário; em cada signo dorme este monstro" (1978, p.15). Na ótica do inaugurador da semiologia literária, "na língua, portanto, servidão e poder se confundem inelutavelmente" (1978, p.15) e, no dia a dia, disso não se foge.

Para o escritor moçambicano, "fiar um texto" permite-lhe a reestruturação da língua, em um percurso artístico, que dá, à sua poética, constantes interpolações de sentidos, promovendo caminhos que se cruzam e misturam diferenças, tempos, raças, enfim, signos, reconfigurando relações de significantes e significados - e, por que não, interpretantes - em mundos multifacetados. Logo, a partir dos múltiplos signos que invadem e se constroem em sua poética, Mia tece habilmente as aspirações do universo que o rodeia, "desalisando" a linguagem e gozando as "idimensões" da vida.

Ele dá conta disso e denuncia que

Vivemos dominados por uma percepção redutora e utilitária que converte os idiomas num assunto técnico da competência dos linguistas. Contudo, as línguas que sabemos - e mesmo as que não sabemos que sabíamos - são múltiplas e nem sempre capturáveis pela lógica racionalista que domina o nosso consciente. Existe algo que 
escapa à norma e aos códigos. Essa dimensão esquiva é aquela que a mim, enquanto escritor, mas me fascina. O que me move é a vocação divina da palavra, que não apenas nomeia mas que inventa e produz encantamento. (COUTO, 2009, p.16)

Na obra miacoutiana, "a língua não se esgota na mensagem que engendra; que ela pode sobreviver a essa mensagem e nela fazer ouvir, numa ressonância muitas vezes terrível, outra para além do que é dito, super-imprimindo à voz consciente, teimosa, implacável da estrutura, isto é, da espécie enquanto falante" (BARTHES, 1978, p.14). Assim, como já apontara Barthes, ao falar da literatura em geral, encontra-se, na obra de Mia Couto, "essa trapaça salutar, essa esquiva, esse logro magnífico que permite ouvir a língua fora do poder, no esplendor de uma revolução permanente da linguagem" (BARTHES, 1978, p.16), tem-se aquilo que Barthes chamou, "quanto a si", de "“" (BARTHES, 1978, p.16).

Mia sabe que "estamos todos amarrados aos códigos colectivos com que comunicamos na vida quotidiana. Mas quem escreve quer dizer coisas que estão para além da vida quotidiana" (COUTO, 2009, p.16), e "o texto é o próprio aflorar da língua, é no interior da língua que a língua deve ser combatida, desviada: não pela mensagem de que ela é o instrumento, mas pelo jogo das palavras de que ela é o teatro" (BARTHES, 1978, p.17). E o escritor moçambicano demonstra reconhecer a encenação das palavras nos cenários de linguagem do quotidiano, dando-lhes vida e história:

as palavras nascem, mudam de rosto, envelhecem e morrem. É importante saber onde nasceu cada uma delas, conhecer-lhe os parentes e saber do namoro que a fez nascer. Entender a origem e a história das palavras faz-nos ser mais donos de um idioma que é nosso e que não apenas dá voz ao pensamento como já é o próprio pensamento. Ao sermos donos das palavras somos mais donos da nossa existência. (COUTO, 2009, p.103)

E, assim, ele faz das palavras aquilo que bem quer, com o prazer lúdico do jogo ficcional, muito próximo do que, certa vez, Luís Fernando Veríssimo, um talentoso escritor brasileiro, andado pelas sendas das crônicas de humor, 
admitira fazer.

Em entrevista dada a alunos da educação básica, quando perguntado sobre suas relações com a gramática, a língua, as palavras, Luís Fernando respondeulhes, dizendo que "a intimidade com a Gramática é tão dispensável que eu ganho a vida escrevendo apesar da minha total inocência na matéria. Sou um gigolô das palavras. Vivo às custas delas. E tenho com elas a exemplar conduta de um cáften profissional. Abuso delas" (VERÍSSIMO, 1985, p.15). Ainda segundo o escritor brasileiro, "as palavras [...] não merecem o mínimo respeito" (VERÍSSIMO, 1985, p.15).

É claro que Veríssimo fala de seu lugar de artista da palavra, e toda a sua "brincadeira" com o uso normativo da língua tem anteparo em seu emprego no texto literário. Para ele, o escritor não deve prestar obediência à língua, respeitando sua ordenação gramatical normativa, imposta pelas regras do uso padrão, como indicam os gramáticos, mas valer-se dela para exercitar-se nos jogos da ficção. Luís Fernando acha, ainda que gracejamente, que "a Gramática precisa apanhar todos os dias para saber quem é que manda" (VERÍSSIMO, 1985, p.16).

É, pois, nesse mesmo sentido, que Mia Couto sustenta que:

As palavras e os conceitos são vivos, escapam escorregadios como peixes entre as mãos do pensamento. E como peixes movem-se ao longo do rio da História. Há quem pense que pode pescar e congelar conceitos. Essa pessoa será quanto muito um colecionador de ideias mortas. (COUTO, 2005, p.85)

Mas o escritor nunca o é. "O dever do escritor para com a língua é recriála, salvando-a dos processos de banalização que o uso comum vai estabelecendo" (COUTO, 2005, p.111). A recriação pregada por Mia alinha-se à "terceira força da literatura", apresentada por Barthes, quando fala do caráter semiológico da linguagem literária. Nas palavras do estudioso francês:

Pode-se dizer que a terceira força da literatura, sua força propriamente semiótica, 
consiste em jogar com signos em vez de destruí-los, em colocá-los numa maquinaria de linguagem cujos breques e travas de segurança arrebentaram, em suma, em instituir no próprio seio da linguagem servil uma verdadeira heteronímia das coisas. (BARTHES, 1978, p.28-29)

No caso específico das literaturas africanas das ex-colônias portuguesas, dos PALOP - Angola, Cabo Verde, Guiné-Bissau, Moçambique e São Tomé e Príncipe -, a questão da língua de cultura - não em seu sentido qualitativo, mas, inevitavelmente, tornemos a Barthes, em seu sentido de poder - é de capital importância. O idioma oficial não representa, fatualmente, a identidade linguística das terras, pois, como advertiu Mia Couto, referindo-se a Moçambique:

O meu país é um território de muitas nações e muitas línguas (mais de vinte diferentes idiomas). O idioma português é a língua de uma dessas nações - um território cultural inventado por negros urbanos, mestiços, indianos e brancos. Sendo minoritário e circunscrito às cidades, esse grupo ocupa lugares chaves nos destinos políticos e na definição daquilo que se entende por moçambicanidade. A língua portuguesa não é ainda a língua de Moçambique. Está-se exercendo, sim, como a língua da moçambicanidade. (COUTO, 2007, p.20)

Mas o escritor vai-se expressar nessa língua, que cruza mares e oceanos, adentra continentes, o "português, língua que todos falavam, bem ou mal" (PEPETELA, 1982, p.30).

Mia Couto assume-se um ser de entrelugar, híbrido, mosaico:

Sou moçambicano, filho de portugueses, vivi o sistema colonial, combati pela Independência, vivi mudanças radicais do socialismo ao capitalismo, da revolução a uma guerra civil que demorou 16 anos e fez um milhão de mortos. Nasci num tempo de charneira, entre um mundo que nascia e outro que morria. (COUTO, 2007, p.17)

E admite: "cresci nesse ambiente de mestiçagem, escutando os velhos contadores de histórias" (COUTO, 2005, p.150), onde colheu as bases de seu ofício de escritor. Ao falar de sua cidade natal, a Beira moçambicana, ainda adverte que, 
No fundo eu partilhava com a cidade uma igual condição: ambos éramos criaturas de fronteira, entre o mar e a terra, entre o rural e o urbano, entre a Europa e a África. Sou moçambicano, filho de portugueses, nasci em pleno sistema colonial, [...] A cidade é um cordão umbilical que criamos depois de nascermos. Cresci nesse ambiente de mestiçagem, escutando os velhos contadores de história. Eles me traziam o encantamento de um momento sagrado. Filho de um poeta ateu, aquela era a minha missa, aquele era o recado do divino. (COUTO, 2005, p.150)

Mas ele não deixa de se lastimar: "Os meus antepassados estão enterrados em outro lugar distante, algures no Norte de Portugal. Eu não partilho de sua intimidade [a intimidade dos deuses da terra africana] e, mais grave ainda, eles me desconhecem inteiramente" (COUTO, 2005, p.151).

Todavia, nascido e criado em Moçambique, filho de pais portugueses, Mia Couto enfrenta, frente a frente, três, dentre muitos outros, fantasmas que rondam sua existência. Conforme aponta, "identidades, língua, marcas culturais [...] são três fantasmas partilhando a mesma cama. E quando se entra no quarto, acreditando surpreendê-los em flagrante delito eis que descobrimos que não há cama, nem quarto, nem amantes" (COUTO, 2007, p.11). Ele tem consciência de que "aquilo que chamam a nossa identidade [,] grande parte das vezes [...] é uma casa mobilada por nós, mas a mobília e a própria casa foram construídas por outros" (COUTO, 2005, p.14). Logo, reafirma:

A minha língua portuguesa, repito a minha língua portuguesa, é a pátria que estou inventando para mim. Essa língua nómada é viagem viajada, namoradeira de outras vozes e outros tempos. O importante não é tanto a língua, nem sequer o quanto ela nos é materna. Mais importante é essa outra língua que falamos mesmo antes de nascermos. Nesse registro está a porta e o passaporte em que todos nos fazemos humanos, fabricadores da palavra e, com igual mestria, criadores de infinitas identidades. (COUTO, 2007, p.20)

Desponta, assim, o escritor Mia Couto, cuja "condição sempre foi a de criatura de fronteira. As duas partes de mim exigiam um medium" (COUTO, 2007, p.17), disse ele, para quem: 
É verdade que grande parte dos escritores africanos enfrenta desafios para ajustar línguas e culturais diversas. Mas esse problema não é exclusivo nosso, os de África. Não existe escritor no mundo que não tenha de procurar uma identidade própria entre identidades múltiplas e fugidias. Em todos os continentes, cada homem é uma nação feita de diversas nações. Uma dessas nações vive submersa e secundarizada pelo universo da escrita. (COUTO, 2009, p.25)

E sua escrita é marcada pela desconstrução/reconstrução da língua, valendo-se das possibilidades combinatórias do sistema linguístico - langue, na acepção saussuriana -, representado em usos - parole, igualmente na acepção saussuriana -, imprevistos, surpreendentes, enigmáticos. Trata-se de algo um tanto mágico ou místico, que induz a linguagem ao êxtase do transe. $\mathrm{Na}$ concepção de Mia Couto,

Mais que a invenção de palavras, o que me tocou foi a emergência de uma poesia que me fazia sair do mundo, que me fazia inexistir. Aquela era uma linguagem em estado de transe, que se deixava possuir como os mediuns das cerimónias mágicas e religiosas. Havia como que uma embriaguez profunda que autorizava a que outras linguagens tomassem posse daquela linguagem. Exactamente como o dançarino da minha terra que não se limita a dançar. Ele prepara a possessão pelos espíritos. $\mathrm{O}$ dançarino só dança para criar o momento divino em que ele emigra do seu próprio corpo. (COUTO, 2007, p.18)

Será esse, no todo, o caráter poético da obra miacoutiana, inaugurada, em 1983, com o volume de poesias Raiz de orvalho, a que se seguiu, em 1986, a reunião de contos Vozes anoitecidas. Em 2003, “com o pequeno grande livro $O$ Gato e o Escuro, o escritor moçambicano [...] estreia-se no mundo da literatura infantil" (SILVA, 2003, p.253), o que "representa o acesso do autor a uma nova matriz literária [...], a da literatura infanto-juvenil” (ALBUQUERQUE, 2004, p.159).

A propósito de sua estreia, Mia assim se posiciona:

Não sei se alguém pode fazer livros "para" crianças. Na verdade, ninguém se apresenta como fazedor de livros "para" adultos. O que me encanta no acto da escrita é surpreender tanto a escrita como a língua em estado de infância. E lidar com o idioma como se ele estivesse ainda em fase de construção, do mesmo modo que uma criança converte o mundo inteiro num brinquedo. Eu penso assim e, por todas estas razões, nunca acreditei que, um dia, eu escreveria uma história que iria constar de um 
livro infantil. Mas sucedeu assim. À força de contar histórias para meus filhos adormecerem, inventei uma convicção para mim mesmo e acredito que invento histórias para que a terra inteira adormeça e sonhe. O escritor traria, assim, o planeta ao colo. $(2008$, p. 5)

A nova aventura a que o escritor se lança segue o mesmo percurso de suas demais produções. Nela,

seu discurso é esculpido com uma delicadeza evidente, o que se comprova, por exemplo, através de uma "inventividade" - em muitos momentos, ludicidade - no plano vocabular (característica, aliás, subjacente à totalidade da sua escrita e já apelidada como um conjunto de "brincriações do maravilhoso"), ao serviço de uma narração inovadora que parece ser dedicada às crianças. (SILVA, 2003, p.253 - grifo nosso)

E, de fato, manifestam-se, igualmente,

algumas características muito gerais da Literatura Africana [...]: a primeira dessas características advém do facto de todas as literaturas africanas actuais serem produto de um conflito entre poderes coloniais e culturais indígenas, o que provoca nelas uma tendência libertária e reflexiva; a segunda característica é servirem de veículo a forças de nacionalismo, que enfatizam temáticas da Cultura tradicional, debruçando-se mesmo sobre vozes arquetipais. (ALBUQUERQUE, 2004, p.159)

Claro e escuro, amarelo e preto são arquétipos inerentes à problemática africana, refletidos na maior parte da ficção das ex-colônias portuguesas em África e, notadamente, presentes na absoluta totalidade da obra de Mia Couto. "Pintalgato [, a personagem principal,] procura [, arquetipicamente,] uma identidade com uma busca de alteridade" (ALBUQUERQUE, 2004, p.168). É apresentado como um ser híbrido, mestiço, mosaico, resultado do trânsito que empreende em direção ao desconhecido assustador.

Dessa forma, poder-se-ia, desavisadamente, anular a destinação do texto ao público infantil ou, ainda, reduzir sua leitura interpretativa às impressões mais comuns, de caráter moralista ou didático, identificando-o como discurso contrário à desobediência de um filho frente aos conselhos e proibições de sua mãe. Mas ficar por aqui, como muito já se ficou, é empobrecer as leituras 
intertextuais que a narrativa permite, principalmente depois de o autor se ter lançado na seara dos artigos de opinião, como ele mesmo nomeou os conjuntos de texto em que se coloca não como ficcionista, mas desnudo da arte de "brincriar".

$O$ gato e o escuro pode ser lido sob perspectivas autobiográficas, ilustrando o trânsito experienciado pelo próprio autor, filho de brancos portugueses - cabelos louros e olhos claros - a moçambicano assumido, ser da África negra. As evidências de inter-relações entre António Emílio Leite Couto e os gatos - que ele queria ou se fazia ser - são abundantes no conjunto de seus textos. Conforme ele mesmo relata:

Aos dois anos de idade tive a infeliz ideia de reclamar um novo nome para mim mesmo. Contra o António de nascença - eu inventei um outro nome: Mia. Rebatizeime com esse nome em celebração com a minha vivência com os gatos da vizinhança. Não é que eu gostava de gatos. Eu acreditava ser gato. Eu não pensava: eu era um gato. (COUTO, 2007, p.13)

Mia entende que "a infância não é um tempo, não é uma idade, uma colecção de memórias. A infância é quando ainda não é demasiado tarde. É quando estamos disponíveis para nos surpreendermos, para nos deixarmos encantar" (COUTO, 2009, p. 110). Foi nesse tempo de infância que os gatos se lhe tomaram, pois, como ele conta:

$\mathrm{Na}$ minha infância acreditava ser gato. Eu não pensava; eu era um gato. Para testemunho deste delito de identidade, meus pais guardam provas documentais: fotos minhas comendo e dormindo entre os bichos. Fui ensinado a afastar-me do gato que existia dentro de mim.

Depois me inventei outros bichos. (COUTO, 2005, p.195)

E ele, de fato, não queria ser outra coisa:

Ser humano foi talvez o que nunca aspirei. Ao fim de muita insistência lá me resignei. Mas, ao menos fosse bombeiro. Cedo aprendemos um mundo como uma casa ameaçada de incêndio.

eu aspirava ser bombeiro, corrigindo essa fatalidade, salvando não apenas as pessoas, mas a sua 
condição de moradores na eternidade. (COUTO, 2005, p. 195)

Contudo, ao fim e ao cabo,

estava escrito: eu havia de ser homem. Isto é, fui aprendendo a ter medo de ser outra coisa. Encontrei refúgio nas pequenas estórias. Sonhar, sonhar-me, esquecer-me, vencer-me sem ter que lutar contra nada. Através do sonho eu já havia viajado de identidade: já fora bicho, bombeiro e até pessoa. [...] Estava condenado a ter a pátria nesse tempo inicial e iniciador. A infância não é, nesse sentido, um tempo mas um acto de fé, uma devoção. (COUTO, 2009, p.195-196)

O sentimento de medo é, ainda, outro aspecto do texto que favorece sua leitura na linha autobiográfica, pois, como escreve o autor, em prefácio à edição brasileira:

Espero que o gatinho que habita estas páginas possa afastar ideias escuras que temos sobre o escuro. A maior parte dos medos que sofremos, crianças e adultos, foi fabricada para nos roubar curiosidade e para matar a vontade de querermos saber o que existe para além do horizonte.

Esta é uma história contra o Medo. (COUTO, 2008, p. 5)

A persistência do medo do desconhecido, daquilo que se estranha ou ignora, está presente no núcleo significativo de $O$ gato e o escuro. O texto, elaborado pelo moçambicano, permite que se adentrem (n)as tessituras do escuro, da impossibilidade do visível, para discutir-se o olhar infantil diante da relação entre o Eu e o Outro. A configuração portuguesa do escritor reunir-se-ia, portanto, à sua condição de moçambicano, vivendo entre uma multiplicidade de existências, ao traduzir, para o encantado mundo da infância, a experiência híbrida do quotidiano.

Consequentemente, o escritor constrói, em sua narrativa, referências simbióticas entre o seu ontem e o hoje. E, sua necessidade de tornar-se gato, quando criança, retornaria, portanto, na configuração do jovem Pintalgato, que testa seus conhecimentos adentrando (n)a escuridão interdita. Do mesmo modo, o escritor, ao deixar os caminhos de ser bicho, caminha pelas bifurcações da 
palavra, travando, com seus conhecimentos, uma renovação ao buscar-se na cultura do outro, com quem troca em relações híbridas, tal qual os olhos de Dona Gata, em que há bem lá no fundo marcas do "gato preto, enroscado do outro lado do mundo" (COUTO, 2008, p. 37).

Assim, entre o amarelo da pele e o negro da escuridão, são forjados os signos de uma narrativa multifacetada, em que um e outro são irmãos, de experiência, de cor, de vivência e, mesmo, de mãe. Afinal, Dona Gata deixa-se preencher por esse pequeno escuro que habita cada ser humano, presente, também, na existência interior do próprio escritor. Logo, Mia, bem como o gatinho que desejava ser em sua infância, "pinta-se" de escuridão, preenchendo, com novas e diferentes experiências, suas origens. Contudo, sem esquecer-se de seus antepassados, o escritor e o Pintalgato dividem os diálogos possíveis, a convivência harmoniosa entre espaços diversos que se cruzam, quer em um muro, quer no quotidiano.

O muro simbólico, presente em Moçambique, dividiria as experiências, deslocando os homens de seus espaços de sentido. Mia Couto, porém, afirma, em seus textos de opinião, sua condição fronteiriça, quando diz:

O escritor é um ser que deve estar aberto a viajar por outras experiências, outras culturas, outras vidas. Deve estar disponível para se negar a si mesmo. Porque só assim ele viaja entre identidades. E é isso que um escritor é - um viajante de identidades, um contrabandista de almas. Não há escritor que não partilhe dessa condição: uma criação de fronteira, alguém que vive junto à janela, essa janela que se abre para os territórios da interioridade.

O nosso papel é o de criarmos os pressupostos de um pensamento mais nosso... (COUTO, 2005, p. 59)

Como se pode observar em $O$ gato e o escuro, há a (res)simbolização da própria palavra, que se amalgama ou se reformula com elementos autobiográficos. Nesse texto o gatinho, curioso, adentra (n)a escuridão, desobedecendo aos conselhos maternos, da língua mãe, do saber materno ou familiar, para (re)conhecer (n)o espaço do Outro. Assim, o gatinho Pintalgato, 
tal qual seu criador, Mia Couto nasce desse outro lado, tomado por um escuro irmão, que o completa e lhe permite assumir-se (n)esse outro espaço.

Enquanto ser de fronteira Mia estaria sob esse muro, marcado "encantatoriamente" por uma ancestralidade que ele não tem, mas também por uma história sua, marcadamente obtida como imagem de uma vida de trocas e experiências, como se observa quando fala da memória: "Todos trazemos escritos um livro e esse texto quer-se impor como nossa nascente e como nosso destino" (COUTO, 2009, p. 200).

O livro de que trata Mia Couto constituir-se-ia a partir das estruturas de seu $E u$ infantil, que partilha a linguagem em estado de infância e, mesmo, seu $E u$ adulto, composto pelo hibridismo da experiência. Nesse conjunto que há no escritor, compõe-se uma estrutura textual onde, talvez, o gato e o escuro se irmanem, mesclando sentidos diversos dos seres que são, para, então, permitirem que se vejam traços fundamentais da formação do próprio escritor, que, na narrativa simbólica de que trata, "solta o barco e convida para a errância da viagem" (COUTO, 2009, p. 200).

Uma viagem pelo descobrimento do mundo, permeado pela seara insólita da constante efusão do inesperado, haja vista a curiosidade do gatinho, que, apesar de avisado por sua mãe, busca o que não compreende e, ao conseguir entender, questiona o (re)conhecimento da escuridão, qual seja, seu irmão. É, assim também, a experiência de sentidos presente na escrita miacoutiana, que, em uma perspectiva autobiográfica, possibilita a descoberta dos vários mundos existentes no interior do artista da palavra, que (re)cria, por exemplo, o confronto com o medo através de seu combate/embate e, mesmo, da noção de invadir-se por ele.

O escritor, como lembra em seus textos de opinião, é o humano que não desejava ser. Deixando de ser gato, porém, é, de certo modo, o bombeiro de seus mundos. Ao elaborar espaços possíveis e caminhar sob esse muro, do mesmo 
modo que Pintalgato, entre a luz e a escuridão, o autor capacita-se para dedilhar o lado de cá e o de lá, tomando, para si e os outros, os múltiplos elementos da escuridão, guardados, mesmo, em seus olhos, ou seja, em suas experiências.

Mia, ao passear pela literatura infantil, integra os conhecimentos da ancestralidade, do materno, à curiosidade própria da infância, das primeiras e sempre novas descobertas, como se sua ficção pertencesse aos textos da literatura tradicional oral, permeada pelos saberes antigos transmitidos, como afirma Pereira, a meninos curiosos (2006, p. 176). Do mesmo modo, os saberes apreendidos pelo menino curioso Mia Couto, que ao perambular pela descoberta de sua língua, percebendo-a como reconstrução, conseguiu adentrar os signos de um mundo desconhecido para cunhar um espaço, principalmente em $O$ gato e $o$ escuro, de combate ao medo, (n)essa escuridão que assola o desconhecimento diante do amanhã, como discorre Azevedo, ao falar sobre a narrativa:

estabelecendo uma ponte entre o imaginário e o real, a literatura infantil concretiza frequentemente efeitos rítmicos, jogos rimáticos e sugestões fônicos-icónicas da língua, ilustrando e revelando muitos dos matizes semânticos das palavras e da força ilocutiva das metáforas, que as crianças, graças à interacção com os textos aprendem a desvendar e a conhecer intuitivamente. (2006, p. 269)

O gato e o escuro trata do desconhecido de maneira direta, ao revelar a descoberta inicial da infância. Saboreando as infinitas diversidades do viver, faz ver o aprendizado e, também, a metamorfose, em relevo devido às configurações das personagens, que se animam na e pela mudança. A metamorfose, considerada em seus vários matizes, no interior da narrativa, constitui-se pela diferença, marcada, originariamente, pelo teor insólito atribuído às modificações físicas e, poder-se-ia dizer, sensoriais das personagens. Traço sistemático disso é o passo a passo da transformação de Pintalgato que "À medida que avançava, seu coração tiquetaqueava. Temia o castigo. Fechou os olhos e andou assim, sobrancelhado, noite adentro. Andou, andou, atravessando a imensa noitidão" (COUTO, 2008, p. 14). 
A noite invadida por Pintalgato, apesar dos avisos de sua mãe, remete a pretensão de Mia em manter-se gato, durante a infância, permitindo que se observem nos impulsos do gatinho as referências desse escritor que, no intuito de combater os incêndios da opressão, gesta uma ficção cheia de percursos e caminhos, os quais dialogam diretamente com a capacidade humana de transcender os infortúnios ao combater seus próprios medos. Sua narrativa, que habilmente transforma Pintalgato, o curioso, em um frágil jovem tingido em negras cores, também permite que se leiam a capacidade de transcendência das personagens, que não deixam que o escuro se encha com seus próprios medos (COUTO, 2008, p. 28), tornando-os parte, figuras, do arco-íris de Dona Gata. A importância dada a eles pela mãe poder-se-ia dizer que traz à luz seres expropriados de liberdade, deixando, bem como Mia Couto, em seu trabalho com a língua, que os medos sejam esquecidos, ao gerar novas cores para um mundo tomado pela escuridão. Nas palavras de Mia, em Pensatempos:

\begin{abstract}
Este é um momento de abismo e desesperanças. Mas pode ser, ao mesmo tempo, um momento de crescimento. Confrontados com as nossas mais fundas fragilidades, cabenos criar um novo olhar, inventar outras falas, ensaiar outras escritas. Vamos ficando, cada vez mais, a sós com a nossa própria responsabilidade histórica de criar uma outra História. (COUTO, 2005, p. 22)
\end{abstract}

Ao opinar sobre a situação de seu país, Mia demonstra as ideias contrapostas que convivem na constituição de sua nação. $\mathrm{O}$ escritor ao fazer isso permite, ainda, que se percebam os diálogos entre a escuridão enfrentada por Pintalgato, que parece consumi-lo, mas que, no instante seguinte, torna-se parte de sua constituição. O jovem gatinho, bem como o escritor, enfrenta as mazelas que se lhes turvam os caminhos para no momento seguinte (re)estabelecerem-se com os muitos que habitam seus interiores.

A ficção miacoutiana, isto é, a pequena "fábula" da existência e convivência do gato e do escuro, permite profundos mergulhos no teor fantástico do quotidiano, que se engendra gradativamente pela troca entre Pintalgatinho e o 
Escuro. A mãe é aquela que articula os saberes, convivendo com um e com outro, sem temê-los, como detentora de saberes ancestrais. Nesse sentido, a Dona Gata seria símbolo de transição, a provável luz da mudança, que possibilita ao artista antever a capacidade intrínseca contida em cada um para transcender as diferenças entre si e a escuridão, permitindo a transposição das amarras representadas pela rigidez de sentidos em que habitam os medos diante do desconhecido.

\section{Referências}

ALBUQUERQUE, Fátima. “O Gato e o Escuro, de Mia Couto: 'uma estória por via da poesia"”. In: Forma breve, n.2, O poema em prosa, Aveiro, 2004. p.159-169.

AZEVEDO, Fernando Fraga de. "Literatura e promoção da competência literária. Leituras em torno de $O$ gato e o escuro de Mia Couto". In: LARANJEIRAS, Pires; SIMÕES, Maria João; XAVIER, Lola Geraldes (org.). Estudos de literaturas africanas - Cinco povos, cinco nações. Lisboa: Novo Imbondeiro, 2006. p.269-273.

BARTHES, Roland. Aula. São Paulo: Cultrix, 1978.

BAUMAN, Zygmunt. Medo Líquido. Rio de Janeiro: Jorge Zahar, 2008.

COUTO, Mia. 1997, Perguntas à língua portuguesa, Disponível em: $<$ http://www.recantodasletras.com.br/teorialiteraria/3321778http://www.recantodasletra s.com.br/teorialiteraria/3321778 $>$. Acesso em 12/04/2013. . Pensatempos - textos de opinião. 2ed. Lisboa: Caminho, 2005. p.59-63. . O gato e o escuro. São Paulo: Companhia das Letrinhas, 2008.

. E se Obama fosse africano? e outras interinvenções. Lisboa: Caminho, 2009. p.101112.

. "Luso-Afonias - A lusofonia entre viagens e crimes". In: E se Obama fosse africano? e outras interinvenções. Lisboa: Caminho, 2009. p.183-198.

PEPETELA (PESTANHA, Artur). Mayombe. São Paulo: Ática, 1982.

PEREIRA, Cláudia Sousa. "Literatura para crianças e jovens - edições africanas pósindependência e português (primeiras sistematizações)". In: LARANJEIRAS, Pires; SIMÕES, Maria João; XAVIER, Lola Geraldes (org.). Estudos de literaturas africanas - Cinco povos, cinco nações. Lisboa: Novo Imbondeiro, 2006. p.174-180.

SILVA, Sara Raquel D. Reis da. "Mia Couto, O Gato e o Escuro, Editorial". In: Forma breve, n. 1, O conto, Aveiro, 2003. p. 253-254. 
VERÍSSIMO, Luís Fernando. "O gigolô das palavras". In: LUFT, Celso Pedro. Língua e Liberdade (O gigolô das palavras): por uma nova concepção da língua materna. 4ed. Porto Alegre: L\&PM, 1985. p.14-16. 